\title{
The use of music for emotion modulation in mental disorders: the role of personality dimensions
}

\author{
Stefan Gebhardt ${ }^{1 *}$, Markus Kunkel ${ }^{2}$ and Richard von Georgi ${ }^{2,3}$ \\ *Correspondence: Stefan.Gebhardt@uni-marburg.de

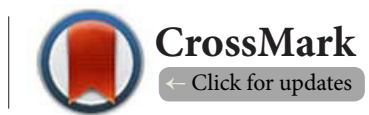 \\ 'Department of Psychiatry and Psychotherapy, University of Marburg, Marburg, Germany. \\ ${ }^{2}$ Department of Music science and Music education, Justus-Liebig-University Giessen, Germany. \\ ${ }^{3}$ International Psychoanalytic University, Berlin, Germany.
}

\begin{abstract}
Background: Until now little has been known about the relationship between emotion modulation through music listening habits and personality dimensions, especially in patients with mental disorders.

Objective: To explore relations between the use of music in everyday life and personality dimensions in patients with mental disorders.

Methods: A population of patients suffering from mental disorders $(n=190)$ was examined using one inventory on emotion modulation by music (IAAM) and another assessing personality dimensions (SKI).

Results: Patients with high ego-strength used music less for relaxation, cognitive problem solving or for reduction of negative activity, similarly patients with high orderliness used it less for cognitive problem solving or for reduction of negative activity, but patients with high confidence used music more for fun stimulation. Patients who reported that they listened to music which improved their symptoms of mental illness showed more ego-strength and orderliness than patients who listened to music that worsened their emotional condition.
\end{abstract}

Conclusions: The study suggests that the personality variables confidence, ego-strength and orderliness are variables for the use of music in a helpful way for emotion modulation.

Keywords: Music, mental disorders, psychiatric, personality, cognitive, emotion, activation, resilience, everyday life, music therapy

\section{Introduction}

Music is a communication medium with a strong emotional influence on the human being. Therefore it is, not farfetched to hypothesize a relationship between personality traits and the individual relating to music. The individual 's behavior towards music develops especially during youth and adolescence [1], accompanying and interacting with the process of socialization and development of personality truaits. In patients with mental disorders or other diseases music has been studied predominantly on a therapeutic basis [2-4], but almost no systematic scientific data exists on the use of music in everyday life (UofM) of individuals suffering from mental disorders.

The term UofM refers to the existence of a learned behavior or active action strategy which is applied consciously by individuals who use music to influence existing everyday states (e.g., positive or negative emotions, affects, arousal, concentration, vigilance or processes of social attachment) $[5,6]$. In everyday life of patients with mental disorders the UofM often has a crucial role. For example, patients with borderline personality disorder consider music very important in their life; using it to affect regulation as a substitute for non-suicidal self-harming behavior [7]. In our previous report we could show that patients with mental disorders use music in order to reduce negative emotions [6]. Thereby the UofM was positively correlated with the severity of the disorder. In another investigation [8], music therapy showed a transfer effect of therapy leading into a changed behavior of UofM, meaning that patients deal in a more helpful way with music in their everyday life after the application of music therapy. This would imply that music therapy might have a strong residual therapy effect beyond the phase of music therapy. Considering that music is ubiquitous, the research on the UofM certainly has a strong impact on public health. 
The aim of the current investigation was to explore the relationship between the UofM in everyday life and personality dimensions in patients suffering from mental disorders.

Three main topics were explored in this cross-sectional designed study:

1. Analysis of correlation between variables of the UofM and personality dimensions.

2. Influence of age and gender on SKI/IAAM scales.

3. Differences in SKI/IAAM scales with respect to the following variables: emotion modulation of mental condition before and after onset of the mental disorder; musicality; individual value of music; active listening to music vs. passive hearing of music in the background.

\section{Methods}

\section{Subjects}

Of $n=312$ asked patients $n=190$ patients $(61 \% ; 111$ female and 79 male; mean age $37.4 \pm 13.3$ years, range $18-82$ years) admitted at the Department for Psychiatry and Psychotherapy of the University of Marburg, Germany, participated in the study carried out in 2005 until 2007. No patient of the study was treated with music therapy during the actual inpatient treatment. The patients suffered from mood affective disorders (36.4\%), neurotic disorders (24.2\%), disorders of adult personality and behavior (17.9\%), schizophrenia spectrum disorders (12.2\%), psychoactive substance use (6.3\%), and others. Gender and age within the study group did not correlate significantly. Patients gave written informed consent; the study was approved by the Ethics Committee of the University of Marburg, Germany.

\section{Assessment and instruments}

Patients received self-assessment questionnaires. The "Inventory for the assessment of Activation and Arousal modulation through Music" (IAAM) with 62 items on a 5-point-scale showing high reliability and validity [5,6,9-13] measured the situation-dependent everyday life UofM according to the parameters Relaxation (RX), Cognitive Problem Solving (CP), Reduction of negative Activation (RA), Fun Stimulation (FS) and Arousal Modulation (AM). Personality dimensions were assessed by means of the self-concept inventory (SKI [14]). The SKI is designed to register that part of the personality which results mainly from interpersonal interaction. The 5 scales, each containing 8 bipolar items on a 7-point-scale, cover the following dimensions with sufficient reliability coefficients (Cronbach's Alpha) in the present sample: ego-strength vs. insecurity (E-I) (sense of personal and existential security together with the lack of feelings of anxiety; $\alpha=0.79$ ), attractiveness vs. marginality (A-M) (self-assessment of own worth in social groups; $a=0.90$ ), confidence vs. reserve (C-R) (attachment capacity and intimacy; $\mathrm{a}=0.85$ ), orderliness vs. insouciance $(\mathrm{O}-\mathrm{I})$ (degree of structuring in personal environment; $\mathrm{a}=0.78$ ) and enforcement vs. cooperation (E-C) (self-assessment of assertiveness in social groups; $a=0.74)$. Another short questionnaire gathered data on sub- jective impressions on emotion modulation by UofM before and after onset of the mental disorder. Sociodemographic data and data on the mental disorder were taken from the medical records. The Global Assessment of Functioning Scale (GAF) [15] was used to assess the functioning level of the patients.

\section{Statistical procedures}

As statistical procedures Pearson's correlations were used to explore relationships between the IAAM and SKI scales, two-tailed Student's t-tests and chi-quadrat-tests to find out group differences, e.g., in gender. In this exploratory study the term "significant" was used for results with a p-value of $\leq 0.05$. The data were analyzed using Statistical Package of the Social Sciences (SPSS 18.0 for Windows) software.

\section{Results}

Evaluating the correlation analysis we found the following results (see Table 1): the SKI scale E-I correlated negatively with the IAAM scales RX ( $r=-0.174 ; p=0.031), C P(r=-0.215$; $p=0.008)$ and $R A(r=-0.222 ; p=0.006)$. This suggests that patients with a high ego-strength use music less to relax, to solve problems or to reduce negative activation than patients characterized by more insecurity. Further, C-R correlated positively with $\mathrm{FS}(r=0.331 ; p<0.001)$ suggesting that patients with high confidence are more able to use music for fun stimulation than reserved patients. O-I correlated negatively with $C P(r=-0.182 ; p=0.025), R A(r=-0.225 ; p=0.005)$ and-as a trend-AM $(r=-0.155 ; p=0.065)$, what can be interpreted that patients with high orderliness do rather not listen to music to solve problems, to reduce negative activation or for arousal modulation. Interestingly, attractiveness correlated positively with all IAAM scales $(r=0.159-0.312 ; p<0.001-0.049)$.

Correlation analysis of the SKI/IAAM scales with age revealed the following results: the older the patients were, the more pronounced were the variables ego-strength $(E-I ; r=0.210$; $p=0.006$ ) and orderliness (O-I; $r=0.237 ; p=0.002)$, but the less pronounced was the UofM for reduction of negative activity (RA; $r=-0.276 ; p<0.001$ ), for fun seeking ( $F S ; r=-0.242 ; p=0.001$ ), for arousal modulation (AM; $r=-0.168 ; p=0.037$ ) and-as a trend-for cognitive problem solving ( $C P ; r=-0.136 ; p=0.081$ ).

T-tests with SKI/IAAM scales as dependent variables and gender as independent variable displayed significant differences for ego-strength $(E-I)$, which was stronger in the male patient group (mean difference $3.8 \pm 1.3$ points; $p=0.004$ ) and as a trend in relaxation (RX), which was stronger in the female patient group (mean difference $2.7 \pm 1.5$ points; $p=0.071$ ).

In further t-tests we assessed the role of the modulation of their mental condition (as the independent variable): Patients, who reported that they listened before the onset of mental ill-ness to music that improved their mental illness showed no differences in SKI-scales compared to patients who listened to music which worsened their emotional condition. Patients, who reported that they listened during times of mental illness to music that improved their mental illness showed more ego- 
Table 1. Results of the correlation analysis between IAAM and SKI scales.

\begin{tabular}{|c|c|c|c|c|c|}
\hline IAAM SKI & $\mathbf{R X}$ & $\mathrm{CP}$ & RA & FS & AM \\
\hline \multicolumn{6}{|l|}{ E-I } \\
\hline $\mathrm{r}$ & -0.174 & -0.215 & -0.222 & -- & -- \\
\hline $\mathrm{p}$ & 0.031 & 0.008 & 0.006 & n.s. & n.s. \\
\hline $\mathrm{n}$ & 153 & 150 & 154 & -- & -- \\
\hline \multicolumn{6}{|l|}{ A-M } \\
\hline $\mathrm{r}$ & 0.212 & 0.212 & 0.159 & 0.312 & 0.188 \\
\hline $\mathrm{p}$ & 0.008 & 0.009 & 0.049 & $<0.001$ & 0.026 \\
\hline $\mathrm{n}$ & 155 & 150 & 154 & 154 & 140 \\
\hline \multicolumn{6}{|l|}{ C-R } \\
\hline $\mathrm{r}$ & -- & -- & -- & 0.331 & -- \\
\hline $\mathrm{p}$ & n.s. & n.s. & n.s. & $<0.001$ & n.s. \\
\hline $\mathrm{n}$ & -- & -- & -- & 155 & -- \\
\hline \multicolumn{6}{|l|}{ O-I } \\
\hline $\mathrm{r}$ & -- & -0.182 & -0.225 & -- & -0.155 \\
\hline $\mathrm{p}$ & n.s. & 0.025 & 0.005 & n.s. & 0.065 \\
\hline $\mathrm{n}$ & -- & 152 & 155 & -- & 142 \\
\hline \multicolumn{6}{|l|}{ E-C } \\
\hline $\mathrm{r}$ & -- & -- & -- & -- & -- \\
\hline $\mathrm{p}$ & n.s. & n.s. & n.s. & n.s. & n.s. \\
\hline $\mathrm{n}$ & -- & -- & -- & -- & -- \\
\hline
\end{tabular}

RX: Relaxation; CP: Cognitive problem solving; RA: Reduction of negative activation; FS: Fun stimulation; AM: Arousal modulation; E-I: Ego-strength vs. insecurity; A-M: Attractiveness vs. marginality; C-R: Confidence vs. reserve; O-I: Orderliness vs. insouciance; E-C: Enforcement vs. cooperation; n.s. $=$ non-significant

strength (mean difference $5.0 \pm 1.8$ points; $\mathrm{p}=0.009$ ) and more orderliness (mean difference $3.7 \pm 0.9$ points; $p=0.031$ ) than patients who listened to music that worsened their emotional condition. At the same time we found a positive correlation of age and the patients' impression that music during the illness has harmed and not helped $(r=0.199 ; p=0.010)$.

Furthermore, we investigated using t-tests differences in SKI/IAAM scales ( 1 ) between patients who consider themselves musical ( $n=97)$ compared to patients who do not $(n=84)$, (2) between patients who give listening to music a great impact in their life $(n=132)$ compared to those who do not $(n=52)$, and (3) between patients who reported active listening to music $(n=72)$ versus passive hearing of music in the background $(n=58)$ during the time after the onset of the mental disorder.

1. It could be revealed that patients who consider themselves musical show exclusively higher values in attractiveness (A-M; mean difference: $3.4 \pm 1.7$ points; $\mathrm{p}=0.042$ ) and-as trends-in RX (trend; mean difference: $2.9 \pm 1.5$ points; $\mathrm{p}=0.056$ ) und RA (trend; mean difference: $2.7 \pm 1.6$ points; $p=0.096$ ) compared to patients who do not consider themselves as musical.

2. Patients for whom the UofM has a great impact in their life consider themselves more attractive (A-M; mean difference: $3.9 \pm 1.8$ points; $p=0.035$ ), but with more insecurity ( $E-l ;$ mean difference: $-3.6 \pm 1.4$ points; $p=0.012$ ) and show higher values in all IAAM scales (all $p<0.001$; RX: mean difference: $10.3 \pm 1.4$ points; $C P$ : mean difference: $11.2 \pm 1.4$ points; RA: mean difference: $10.6 \pm 1.6$ points; FS: mean difference: $6.2 \pm 1.5$ points; AM: mean difference: $6.8 \pm 1.4$ points), than those patients for whom the UofM has no particular impact in their life.

3. Patients who reported active listening to music showed increased values in the IAAM scales RX ( $p=0.013$; mean difference: $3.9 \pm 1.6), C P(p=0.034$; mean difference: $3.5 \pm 1.6)$ and as a trend RA ( $p=0.095$; mean difference: 2.9 \pm 1.7 ) compared to patients who reported passive hearing of music in the background. Additionally, in a chiquadrat test we found significant more people who reported both that they have listened actively to music and that music have helped them compared to patients who have heard music in the background and who did not profit from music $(p=0.001)$. However, in another item about the question whether music has harmed the patients, we found no significant difference between patients who listened actively to music and those with music in the background. Thus, music which is listened actively-comparable to mindfulness training-can be judged as useful, while music in the background does not help, but-in our sample-has not harmed either.

In the SKI scales there were no differences between the two groups. Further, correlation analysis between SKI scales and the GAF score revealed no significant correlations.

\section{Discussion}

To our knowledge this is the first study investigating relations between the UofM and personality dimensions in a psychiatric population. The study shows that these relations are quantifiable. First exploratory results are provided.

The results of the correlation analysis on relations between variables concerning the UofM and such on personality dimensions suggest that ego-strength and orderliness are connected with less UofM for relaxation, cognitive problem solving, reduction of negative activity and arousal modulation.

One could hypothesize that ego-strength and orderliness might represent a lack of interest in music. However t-tests showed no significant difference in these variables between patients who reported listening to music to be of great impact on their life and those who did not.

We therefore postulated that ego-strength and order-liness might represent resilience personality traits which help to establish the right mood stabilizing techniques even when global functioning is already low. The further result that patients with more ego-strength and orderliness use the appropiate music to improve their mood, falls in line with this assumption. 
Gebhardt et al. Journal of Integrative Psychology and Therapeutics 2014, http://www.hoajonline.com/journals/pdf/2054-4723-2-5.pdf

However, the used mood stabilizing techniques must not only be UofM, but also other techniques of emotion modulation. Thus, people with increased ego-strength and orderliness might have a high degree of structuring abilities, so that they intuitively listen to that kind of music which they consider helpful. This hypothesis is additionally supported by the result that high confidence is connected with greater fun stimulation by means of music.

Interestingly, we found positive correlations of age with both ego-strength and orderliness as well with the patients impression that music during the illness has harmed them. Thus, patients who have higher scores in ego-strength and orderliness seem to have generally the impression that they use helpful music and do not need to reduce negative emotions through music, but when they get older, they experience music during the illness as more harmful. It can not be excluded that patients with higher scores in ego-strength and orderliness can use music positively as long they are healthy together with other strategies, but that they fail to use music as a technique to reduce negative emotions, when they have fallen ill, especially as older patients.

In contrast, patients with more insecurity or insouciance obviously struggle to get relief by UofM, however without success. Nevertheless, patients with higher scores of insecurity report a high impact of UofM in their life. This could reflect a pathomechanism of mental disorders: these patients have lost their natural abilities of keeping themselves in a cognitiveemotional equilibrium including the healthy handling with music. Insecurity could be related to a susceptibility to give oneself up and to be particularly sensible for the strong emotional influences such as the medium music. Insecurity could also be a feature of the mental disorder and the need for emotional coping mechanisms (e.g., through music) resulting hereof.

Interestingly, attractiveness appears to be a major feature of using music for emotion modulation. As well, patients who consider themselves musical and for whom listening to music has a great impact in their life find themselves to be attractive. This evokes the idea of Charles Darwin that music abilities might have evolutionary advantages by impressing the other gender though this theory is of minor interest today. Nevertheless, this cluster of musical abilities and positive emotional traits as attractiveness combined with skills of relaxation and reduction of negative emotions by music could reflect a neurobiological pathway such as the so called Behavioral Activation/Facilitation System (BAS/BFS [16-20]) which appears to be associated with heightened activity of the mesolimbic dopaminergic system [21].

To our knowledge, no studies have investigated the influence of personality dimensions on the UofM in mental disorders so far. Some studies have just examined the influence of music preferences on mental disorders. For example, one study found an association between popular music exposure and major depression while reading print media such as books were negatively associated with depression [22]. We interpret this phenomenon as a result of not listening actively to music, whereas in our current study we investigated in particular UofM as an active strategy of listening to for emotion modulation.

For music therapists it might be interesting to know which personality dimensions their patients have. Patients with high scores in confidence do certainly benefit from music which stimulates fun seeking, probably also patients with high egostrength and orderliness. These patients might intuitively choose the right UofM in order to modulate their emotional state. However, older patients with increased ego-strength and orderliness scores might have problems using music for the reduction of negative emotions during a phase of mental disorder, so that they need specific instruction how to deal with music. Patients with high scores of insecurity might in particular profit from music therapy because they have a strong subjective relation to UofM, but have obviously underrepresented strategies how to use music in the right manner in order to reduce negative emotions (instead of enhancing negative emotions by music).

Further impact on the modulation of emotion have the diagnostic categories, which we have discussed in our previous report [6].

\section{Limitations and strengths}

One limitation is the cross-sectional design without data on all items of a control group (instead of a prospective, controlled design). Therefore, causal relationships cannot be inferred. The listed $p$-values are hence of an explorative nature. However the data represent the real world conditions. Another limitation concerns the interpretation of the results: the correlation coefficients are comparably low $(r=|0.174|-|0.331|)$, which probably reflects the complex dynamics of personality dimensions and emotion modulation strategies which interact among each other and are not constantly present.

The strength of this study consists of the empirical approach on the basis of an emotion modulation concept of UofM. The psychiatric population might show some results in a more focused way than in the general population-the examination of relations between the use of music and personality dimensions might therefore be facilitated.

\section{Conclusions}

The use of music often has a crucial role in the everyday life of patients with mental disorders. For music is a cognitive-emotional entity which both portrays and influences psychological processes, psychiatric pathomechanisms might be additionally unraveled by this approach. This study shows first exploratory data on relations between emotion modulation strategies by means of the use of music in everyday life and personality dimensions.

Overall, results suggest that certain personality dimensions, in particular insecurity and insouciance (lack of structuring capabilities), are connected with the increased use of music to 
cope with negative affective states. However, it is also insecurity and insouciance which seem to avoid successful coping with psychological distress, ending up in a negatively self-reinforcing system, which might reflect a pathomechanism of the mental disorder.

Increasing knowledge about the influence of music on mental disorders might help in leading to a greater relief from mental distress by a more specific handling of music and should also be useful in music therapy. Further studies on the clinical impact of music on the basis of this approach are warranted.

\section{List of abbreviations}

A-M: Attractiveness vs. marginality

AM: Arousal modulation

C-R: Confidence vs. reserve

$\mathrm{CP}$ : Cognitive problem solving

FS: Fun stimulation

GAF: Global assessment of functioning

E-C: Enforcement vs. cooperation

E-I: Ego-strength vs. insecurity

IAAM: Inventory for the assessment of activation and arousal modulation through music

ICD: International classification of disorders

NAD: Non-addiction disorder

O-I: Orderliness vs. insouciance

RA: Reduction of negative activation

RX: Relaxation

SKI: Self-concept inventory

UofM: Use of music in everyday life

\section{Competing interests}

The authors declare that they have no competing interests.

Authors' contributions

\begin{tabular}{|l|c|c|c|}
\hline Authors' contributions & SG & MK & RG \\
\hline Research concept and design & $\checkmark$ & $\checkmark$ & $\checkmark$ \\
\hline Collection and/or assembly of data & $\checkmark$ & $\checkmark$ & $\checkmark$ \\
\hline Data analysis and interpretation & $\checkmark$ & $\checkmark$ & $\checkmark$ \\
\hline Writing the article & $\checkmark$ & -- & $\checkmark$ \\
\hline Critical revision of the article & $\checkmark$ & $\checkmark$ & $\checkmark$ \\
\hline Final approval of article & $\checkmark$ & $\checkmark$ & $\checkmark$ \\
\hline Statistical analysis & $\checkmark$ & -- & $\checkmark$ \\
\hline
\end{tabular}

\section{Acknowledgement}

We thank Prof. Jürgen-Christian Krieg for having supported this study on the patients of the Department of Psychiatry and Psychotherapy, University of Marburg, Germany and Dr. Corinna Illingworth for her helpful, critical comments. There was no funding of the study.

\section{Publication history}

Editor: Kamilla Bargiel-Matusiewicz, University of Warsaw, Poland. Received: 08-Oct-2014 Final Revised: 04-Nov-2014

Accepted: 24-Nov-2014 Published: 01-Dec-2014

\section{References}

1. Gembris H. The development of musical abilities. In: Colwell R, ed. MENC Handbook of Musical Cognition and Development. Oxford University Press, 2006; 124-164. I Book

2. Koger SM, Chapin K and Brotons M. Is Music Therapy an Effective
Intervention for Dementia?A Meta-Analytic Review of Literature. Music Ther. 1999; 36:2-15. I Article | PubMed

3. Pacchetti C, Mancini F, Aglieri R, Fundaro C, Martignoni E and Nappi G. Active music therapy in Parkinson's disease: an integrative method for motor and emotional rehabilitation. Psychosom Med. 2000; 62:386-93. | Article | PubMed

4. Silverman MJ. The influence of music on the symptoms of psychosis: a meta-analysis. J Music Ther. 2003; 40:27-40. | Article | PubMed

5. von Georgi R. Anwendung von Musik im Alltag: Theorie und Validierungsstudien zum IAAM. Marburg: Tectum, 2003. I Pdf

6. Gebhardt S, Kunkel M and von Georgi R. Emotion modulation in psychiatric patients through music. Music Percept. 2014;31: 485-493. I Article

7. Stegemann T, Brüggemann-Etchart A, Badorrek-Hinkelmann A and Romer G. Die Funktion von Musik im Zusammenhang mit selbstverletzendem Verhalten. Praxis der Kinderpsychologie und Kinderpsychiatrie. 2010; 59:810-830. | Pdf

8. Silina A, von Georgi R, Gebhardt S and Weber B. Indirekte Wirkung der Musiktherapie: Transfereffekte auf die Verwendung von Musik im Alltag bei Personen mit psychischen Erkrankungen. Jahrestagung der Deutschen Gesellschaft für Musikpsychologie (DGM), Bremen, 2012; 28-30.

9. von Georgi R, Abou Seif A, Grant P and Beckmann D. Application of music for activation and arousal modulation in everyday life. Abstract Jahrestagung der Deutschen Gesellschaft für Musikpsychologie. 2005.

10. von Georgi R, Grant P, Adjomand G and Gebhardt S. Personality, musical preference and health: First results of the validation of the IAAM. Abstract Jahrestagung der Deutschen Gesellschaft für Musikpsychologie. 2005. I Article

11. von Georgi R, Grant P, von Georgi S and Gebhardt S. Personality, emotion and the UofM in everyday live: Measurement, theory and neurophysiological aspects of a missing link. First studies with the IAAM. Tönning, Lübeck, Marburg: Der Andere Verlag. 2006. I Article

12. von Georgi R. Das Inventar zur Messung der Aktivations-und ArousalModulation mittels Musik (IAAM). In: Schramm H, ed. Medien und Kommunikationswissenschaft-Sonderband 1 "Musik und Medien". Baden-Baden: Nomos, 2007; 138-156. I Website

13. von Georgi R and Lothwesen K S. Use of Music for Emotion Modulation -Testing the validity of the IAAM-scales within different groups of musical preference indicates different qualitative music preference types. Conference Paper at the 13th International Conference for Music Perception and Cognition (ICMPC)-5th Conference of the Asian Pacific Society for the Cognitive Sciences of Music (APSCOM), At Seoul, South Korea, Volume: Moo Kyoung Song (Ed). Book of Abstracts-ICMPC-PSCOM. Seoul: College of Music, Yonsei University. 2014; 29.

14. von Georgi R, Beckmann D. Selbstkonzept Inventar. Bern, Göttingen, Toronto, Seattle: Hans Huber, 2004. I Article

15. American Psychiatric Association (APA). Diagnostic and statistical manual of mental disorders, $4^{\text {th }}$ ed., revised (DSM-IV-TR). Washington, DC: American Psychiatric Press. 2000. I Book

16. Gray JA. The psychophysiological basis of introversion-extraversion. Behav Res Ther. 1970; 8:249-66. I Article I PubMed

17. Gray JA. The psychophysiological nature of introversion-extraversion: A modification of Eysenck's theory of personality. In: Nebylitsyn VD \& Gray JA, eds. Biological bases of individual behaviour. 1972; 182-205. I Book

18. Gray JA. A critique of Eysenck's theory of personality. In: Eysenck HJ, ed. A model for personality. Berlin: Springer. 1981; 246-276. I Article

19. Depue RA and lacono WG. Neurobehavioral aspects of affective disorders. Annu Rev Psychol. 1989; 40:457-92. I Article I PubMed

20. von Georgi R, Göbel M and Gebhardt S. Emotion modulation by means of music and coping behaviour. In: Haas R \& Brandes V, eds. Music that works. Wien, New York, Springer. 2009; 301-319. I Article

21. Depue RA, Luciana M, Arbisi P, Collins $P$ and Leon A. Dopamine and the structure of personality: relation of agonist-induced dopamine activity to positive emotionality. J Pers Soc Psychol. 1994; 67:485-98. | Article | PubMed 
Gebhardt et al. Journal of Integrative Psychology and Therapeutics 2014, http://www.hoajonline.com/journals/pdf/2054-4723-2-5.pdf

22. Primack BA, Silk JS, DeLozier CR, Shadel WG, Dillman Carpentier FR, Dahl RE and Switzer GE. Using ecological momentary assessment to determine media use by individuals with and without major depressive disorder. Arch Pediatr Adolesc Med. 2011; 165:360-5. | Article | PubMed Abstract | PubMed Full Text

\section{Citation:}

Gebhardt S, Kunkel M and von Georgi R. The use of music for emotion modulation in mental disorders: the role of personality dimensions. J Integr Psychol Ther. 2014; 2:5.

http://dx.doi.org/10.7243/2054-4723-2-5 